\title{
Morbidity profile of adolescents reported to an urban health center in Kancheepuram district of Tamil Nadu, India
}

\section{Chinnaian Sivagurunathan, Sekaran Gopalakrishnan*, Ramachandran Umadevi, Pandurangan Mohan Kumar}

\begin{abstract}
Department of Community Medicine, Sree Balaji Medical College \& Hospital Bharath University, Chrompet,
\end{abstract} Chennai-600044, Tamil Nadu, India

Received: 21 August 2015

Revised: 02 September 2015

Accepted: 09 October 2015

\section{*Correspondence: \\ Dr. Sekaran Gopalakrishnan, \\ E-mail: drsgopal@gmail.com}

Copyright: () the author(s), publisher and licensee Medip Academy. This is an open-access article distributed under the terms of the Creative Commons Attribution Non-Commercial License, which permits unrestricted non-commercial use, distribution, and reproduction in any medium, provided the original work is properly cited.

\section{ABSTRACT}

Background: Adolescents are the group of children transforming to adults (aged 10 to 19 years). There are more than 1.2 billion adolescents worldwide and about 243 million live in India i.e. about $20 \%$ of Indian population. They are apparently healthy people but they do also have health related issues. Objective of this study was to determine the morbidity pattern prevalent among adolescents who attended an urban health training centre in Kancheepuram district.

Methods: A cross sectional study was carried among 918 adolescents aged between 10 to 19 years, who visited the urban health training centre during the study period using convenient sampling technique. Data collection was done by using a structured questionnaire which consisted of questions related to their demographic characteristics and the reason for coming to the centre seeking medical help. Data analysis was done using SPSS version 16 and the results expressed in percentages.

Results: Among the study population of $918,57 \%$ were males and $43 \%$ were females. About $81.8 \%$ were studying while $17.7 \%$ were working. About $78.2 \%$ adolescents $(84.3 \%$ of males and $70.1 \%$ females), were suffering from acute conditions while $21.8 \%$ ( $15.7 \%$ males and $29.9 \%$ females) were suffering from chronic conditions. Among the acute conditions, upper respiratory tract infection constituted $22.5 \%$ of complaints followed by musculo-skeletal, gastrointestinal and ENT problems. The most common chronic condition reported was anemia (6.2\%) which was followed by acne on their face and minor psychiatric illnesses like anxiety and depression.

Conclusions: Improvement in the quality of diagnosis and treatment for both acute and chronic illnesses among adolescents are required to be implemented at all levels.

Keywords: Acute illnesses, Chronic illnesses, Teenage, Primary health care

\section{INTRODUCTION}

Globally there are more than 1.2 billion adolescents living in different countries and about 243 million adolescents live in India, which constitute about $20 \%$ of the Indian population. ${ }^{1,2}$ Adolescents are the group of children aged between 10 to 19 years and they are in the phase of transformation into adults. They are apparently healthy people but they also have different kind of problems. Adolescent problems can be broadly grouped in to Physical, Psychological and Social problems. The overall morbidity and mortality among adolescents is increasing day by day due to varied reasons. World Health Organization report says that about 1.3 million adolescents died from preventable or treatable causes. Sexual and reproductive health problems, nutritional 
problems and mental health problems are the major health problems of adolescents. As per NFHS 3 data, about $56 \%$ of girls and $30 \%$ of boys in this group are anemic. About $10.5 \%$ of the girls and $10.8 \%$ of the boys reported having Sexually Transmitted Infections or symptoms of STI and 0.07 percent of the girls and 0.01 percent of the boys in this age group were found to be HIV positive. ${ }^{3}$ A study from Goa, among 16 to 24 years old, shows $3.9 \%$ of youths reported suicidal behaviors with females four times more prone than males. ${ }^{4}$ NFHS-3 data shows, in the age group 15-19, about $11 \%$ of adolescent boys and $1 \%$ of adolescent girls had consumed alcohol, in that $3 \%$ consume it daily and $18 \%$ consume it once a week. About $29 \%$ boys and $4 \%$ girls use some kind of tobacco and $12 \%$ of the boys smoke cigarettes or bidis. The average age at tobacco use initiation was earliest (12.3 years). ${ }^{4}$

Thus it can be seen that the adolescents of today are faced with varied forms of physical, psychological and social problems. With this background we planned to conduct this study to determine the morbidity profile of the adolescent patients attending the urban health training centre in Kancheepuram district.

\section{METHODS}

Study design: This is a community based cross sectional study conducted among adolescents (aged 10 to 19 years) who attended the urban health training centre, Kancheepuram District of Tamil Nadu.

Study area and population: The study area and population comes under the field practice area of our Medical College. The study population identified was the adolescents aged between 10 to 19 years, residing in the study area at the time of the study period. The population of the area is approximately 34560 .

Sampling method and sample size: The study sample was selected from those adolescents who attended the urban health training centre, Kancheepuram district, for a period of three month (15 January 2015 to 15 April 2015). All adolescent patients aged 10 to 19 years attending the outpatient department of the urban health centre, who consented to participate in the study, were included. A total of 918 adolescents patients were interviewed by using the convenient sampling method during the study period.

Tool for data collection: A semi-structured questionnaire was prepared for the data collection. The questions were related to the background characteristics and the purpose of their visit and the final diagnosis made by the medical officer. All the relevant data was recorded by the investigators.

Pilot study: Pre-testing was carried out on thirty adolescents for standardizing the questionnaire. Based on the observations made during the pilot testing, necessary

changes were made in the questionnaire. The results of the pilot test were not included in the final analysis.

Data analysis: Data collected was entered and analyzed using SPSS version 16. Results were expressed by using descriptive statistics. Ethical committee approval and informed consent: The study was approved by institutional ethics committee. Informed consent was prepared in the local language (Tamil) and consent was obtained from the study participants prior to administering the questionnaire.

\section{RESULTS}

Socio-demographic data: The socio-demographic characteristics of the study population are presented in Table 1 and Figure 1. Among the study population of 918 adolescents aged between 10 to 19 years old, $523(57 \%)$ were males and $395(43 \%)$ were females. More than two third of the study participants were aged 15 to 19 years of age [71.4\%]. About $81.8 \%$ (boys-80.5\% and girls-83.5\%) were studying while $17.7 \%$ were working at different levels to earn a livelihood. Among the students, nearly $34 \%$ were studying in colleges or poly techniques. Among those employed, $67.9 \%$ were working as unskilled workers.

Table 1: Demographic profile of the study group of adolescents.

\begin{tabular}{|lllllll|}
\hline $\begin{array}{l}\text { Demographic } \\
\text { variables }\end{array}$ & \multicolumn{2}{l}{$\begin{array}{l}\text { Male } \\
(\mathbf{N}=\mathbf{5 2 3})\end{array}$} & \multicolumn{2}{l}{$\begin{array}{l}\text { Female } \\
(\mathbf{N}=395)\end{array}$} & \multicolumn{2}{l|}{$\begin{array}{l}\text { Both sexes } \\
(\mathbf{N}=918)\end{array}$} \\
\hline Age & $\mathbf{N}$ & $\mathbf{N}$ & $\mathbf{\%}$ & $\mathbf{N}$ & $\mathbf{\%}$ \\
\hline 10-14 & 128 & 24.5 & 135 & 34.2 & 263 & 28.6 \\
\hline 15-19 & 395 & 75.5 & 260 & 65.8 & 655 & 71.4 \\
\hline Education & & & & & & \\
\hline Illiterate & 1 & 0.2 & 2 & 0.5 & 3 & 0.3 \\
\hline Primary & 6 & 1.2 & 4 & 1 & 10 & 1.0 \\
\hline Middle school & 98 & 18.7 & 110 & 27.9 & 208 & 22.7 \\
\hline High school & 79 & 15.1 & 56 & 14.1 & 135 & 14.8 \\
\hline HSC & 144 & 27.5 & 106 & 26.9 & 250 & 27.2 \\
\hline Diploma/collage & 195 & 37.3 & 117 & 29.6 & 312 & 34.0 \\
\hline Career options & & & & & & \\
\hline Student & 421 & 80.5 & 330 & 83.5 & 751 & 81.8 \\
\hline Working: & 98 & 18.7 & 64 & 16.2 & 162 & 17.7 \\
\hline a. Skilled & 12 & 12.3 & 0 & 0 & 12 & 7.4 \\
\hline b. Semiskilled & 27 & 27.5 & 13 & 20.3 & 40 & 24.7 \\
\hline c. Unskilled & 59 & 60.2 & 51 & 79.9 & 110 & 67.9 \\
\hline $\begin{array}{l}\text { Not doing } \\
\text { anything }\end{array}$ & 4 & 0.8 & 1 & 0.3 & 5 & 0.5 \\
\hline Habits & & & & & & \\
\hline $\begin{array}{l}\text { Tobacco use: } \\
\text { 10-14 years }\end{array}$ & 14 & 10.9 & 0 & 0 & 14 & 1.5 \\
15-19 years & 167 & 42.3 & 72 & 27.7 & 239 & 26 \\
\hline $\begin{array}{l}\text { Alcohol use: } \\
\text { 10-14 years }\end{array}$ & 6 & 4.6 & 0 & 0 & 6 & 2.3 \\
15-19 years & 92 & 23.3 & 03 & 1.2 & 95 & 14.5 \\
\hline & & & & & & \\
\hline
\end{tabular}




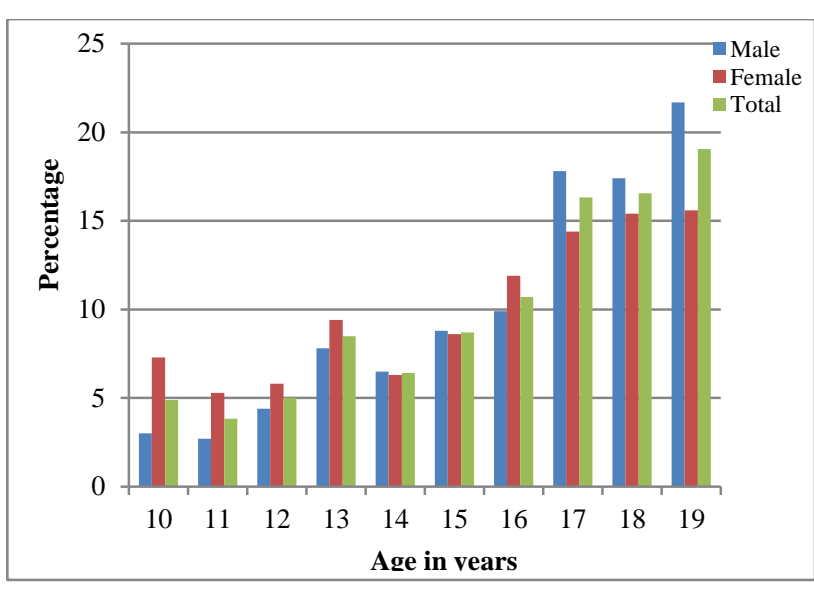

Figure 1: Age-wise distribution of adolescent study group.

Morbidity among adolescents: Table 2 shows the type of illnesses and conditions that made adolescents to visit a Health Centre. About 78.2\% adolescents were suffering from acute conditions while $21.8 \%$ were suffering from chronic conditions. About $84.3 \%$ of males and $70.1 \%$ females had some form of acute conditions while $15.7 \%$ males and $29.9 \%$ females had chronic conditions. Among the acute conditions, upper respiratory tract infection constituted $22.5 \%$ of adolescent complaints followed by musculo-skeletal, gastrointestinal and ENT problems.

The most common chronic condition reported was anemia $(6.1 \%)$ which was followed by presence of acne / pimples on their face $(6 \%)$ and minor psychiatric illnesses like anxiety and depression $(3.9 \%)$. About $6.6 \%$ of the adolescents had some form of genitourinary symptoms like altered appearance of the urine, itchy genitals and burning micturition. About $6.2 \%$ of subjects reported to had skin problem like scabies, pityriasis versicolor etc. No cases of sexually transmitted diseases were recorded. About 5.2\% of the subjects had external injuries, majority of them were boys and most of the external injuries were lacerated wounds due to Road Traffic Accidents and unintentional injuries.

Table 2: Morbidity pattern among adolescents attending the urban health training centre.

\begin{tabular}{|c|c|c|c|c|c|c|}
\hline \multirow[b]{2}{*}{ Conditions } & \multicolumn{2}{|l|}{ Male } & \multicolumn{2}{|l|}{ Female } & \multicolumn{2}{|l|}{ Both sexes } \\
\hline & $\begin{array}{l}\text { Frequency } \\
(\mathbf{N}=\mathbf{5 2 3})\end{array}$ & $\begin{array}{l}\text { Percentage } \\
(\mathrm{N}=57)\end{array}$ & $\begin{array}{l}\text { Frequency } \\
(\mathrm{N}=395)\end{array}$ & $\begin{array}{l}\text { Percentage } \\
(\mathrm{N}=43)\end{array}$ & $\begin{array}{l}\text { Frequency } \\
(\mathrm{N}=918)\end{array}$ & $\begin{array}{l}\text { Percentage } \\
(\mathrm{N}=\mathbf{1 0 0})\end{array}$ \\
\hline Acute conditions & 441 & 84.3 & 277 & 70.1 & 718 & 78.2 \\
\hline $\begin{array}{l}\text { Upper respiratory tract } \\
\text { infection* }\end{array}$ & 143 & 27.3 & 64 & 16.2 & 207 & 22.5 \\
\hline Musculoskeletal system & 48 & 9.2 & 25 & 6.3 & 73 & 8 \\
\hline Gastrointestinal system** & 52 & 10 & 21 & 5.3 & 73 & 8 \\
\hline Ear, nose and throat problems & 44 & 8.4 & 22 & 5.6 & 66 & 7.2 \\
\hline Genitourinary system & 32 & 6.1 & 29 & 7.4 & 61 & 6.6 \\
\hline Skin conditions & 36 & 6.9 & 21 & 5.3 & 57 & 6.2 \\
\hline Gynecology & - & - & 47 & 11.9 & 47 & 5.2 \\
\hline External Injury & 38 & 7.3 & 10 & 2.5 & 48 & 5.2 \\
\hline Dental problems & 21 & 4 & 18 & 4.5 & 39 & 4.2 \\
\hline Eye problems & 18 & 3.4 & 15 & 3.7 & 33 & 3.6 \\
\hline Surgical conditions & 09 & 1.7 & 05 & 1.3 & 14 & 1.5 \\
\hline Chronic conditions & 82 & 15.7 & 118 & 29.9 & 200 & 21.8 \\
\hline Anemia & 26 & 5 & 30 & 7.6 & 56 & 6.1 \\
\hline Acne /Pimples & 15 & 2.9 & 40 & 10.1 & 55 & 6 \\
\hline Minor Psychiatric illness & 11 & 2.1 & 25 & 6.4 & 36 & 3.9 \\
\hline Dermatitis & 13 & 2.5 & 08 & 2 & 21 & 2.3 \\
\hline Bronchial asthma & 11 & 2.1 & 07 & 1.8 & 18 & 2 \\
\hline Seizure disorders & 06 & 1.1 & 08 & 2 & 14 & 1.5 \\
\hline Total & 523 & 100 & 395 & 100 & 918 & 100 \\
\hline
\end{tabular}

*Include pharyngitis, common cold, tonsillitis, laryngitis; **Acute gastroenteritis, acute gastritis

Among the girls' upper respiratory infections [16.2\%], gynecological problems like irregular menstruation, white discharge etc. (11.9\%), presence of acne / pimples on the face $(10.1 \%)$ and anemia $[7.6 \%$ ] were the most common morbidity. Among the boys apart from upper respiratory tract infection [27.3\%], disease related to gastrointestinal 
system like acute gastroenteritis and acute gastritis (10\%), musculoskeletal disorders like myalgia, joint paints $(9.2 \%)$ and conditions of ear nose and throat [8.4\%] were the major problems.

\section{DISCUSSION}

This study conducted among 918 adolescents (age 10 to 19 years) attended urban field practice area of our medical college, for a period of three month (15 January 2015 to 15 April 2015) gives interesting findings. Similar finding was reported by Essai I, who reports that older adolescents' visited primary care centre more often. $^{5}$ In this study, most of the adolescents who attended the primary care center were due to upper respiratory tract infections $(22.5 \%)$ which includes pharangitis, common cold, tonsillitis, laryngitis, followed by musculo-skeletal problems $(8 \%)$, gastrointestinal disorders $(8 \%)$ and Ear, Nose and Throat (ENT) problems $(7.2 \%)$.

Among girls, apart from upper respiratory tract infection, gynecological problems (11.9\%), genitourinary tract infection (7.4\%) and anemia (7.6\%) are the most common cause of morbidity. In Andhra Pradesh, a study done by Susmitha KM et al reported that pallor (41\%), dysmenorrhoea $(43.6 \%)$, dental caries were the leading causes of morbidity in adolescents. ${ }^{6}$ The difference in the morbidity pattern could be due to regional variation. External injuries are common among males, a study from Delhi reported that about $77.5 \%$ of adolescents are at risky behaviors, leading to road-traffic accidents and deaths. $^{7}$

Road traffic accidents has been emerged as the most common cause of morbidity among adolescents which is preventable by simple measures. ${ }^{8}$ Gynecological problems and genitourinary tract infection are common among females, gastrointestinal tract infection is in the top five causes of morbidity among males (Figure 2), this shows the lack of adequate knowledge regarding personal hygiene among adolescents. They should be taught about the importance of personal hygiene at school and community level though various modes of health education.

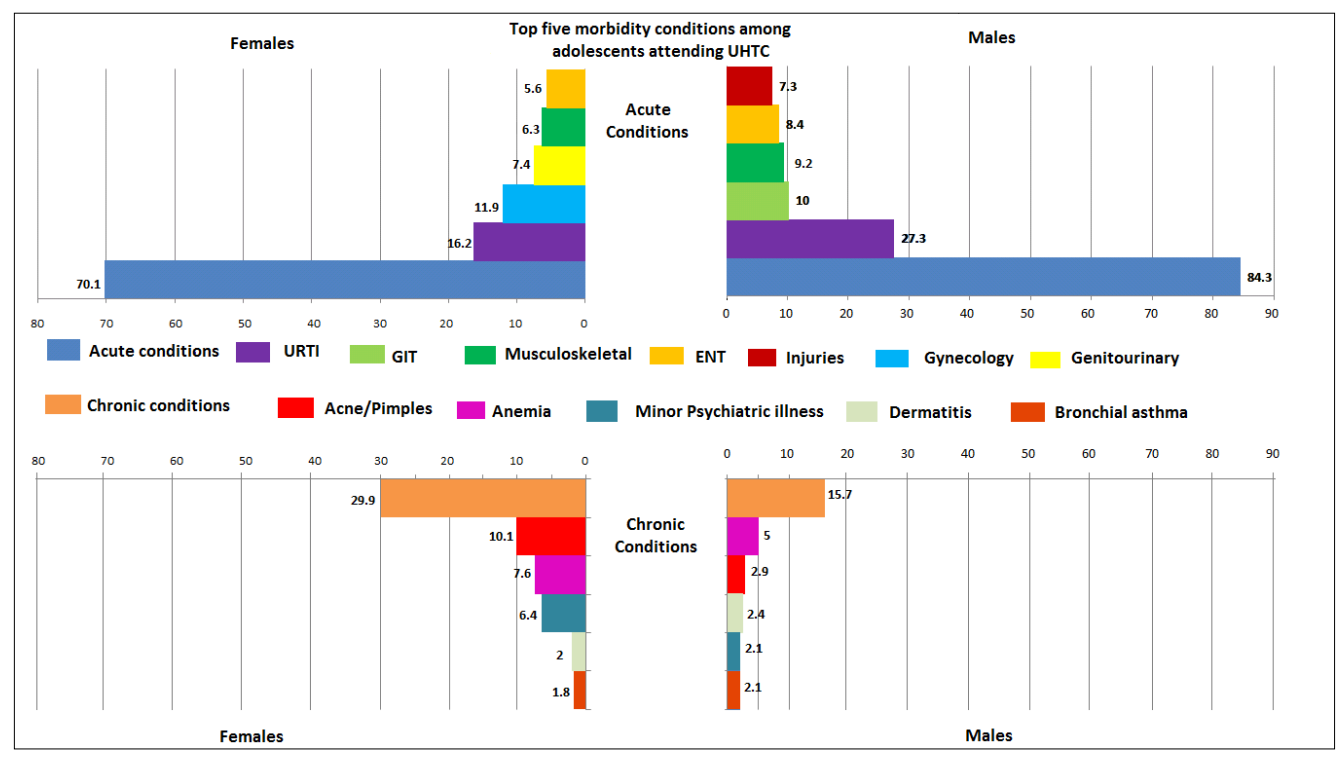

Figure 2: Top five causes of morbidity due to acute and chronic conditions among the adolescents.

No case of sexual transmitted diseases were reported in our study, similar finding was reported by Essai I. ${ }^{5}$ About $10.1 \%$ of adolescent girls reported to have Acne on their face which can lead to bodily dissatisfaction, a major risk factor for depression. ${ }^{9-12}$ About $3.9 \%$ of adolescents are reported to have minor psychiatric illnesses, most commonly depression, which is similar in occurrence compared to studies done in various parts of India. ${ }^{13,14}$

\section{CONCLUSIONS}

Adolescence is a phase of transmission from children to adults. So this phase has to be healthy and disease free, both physically and mentally, to have a bright future. This study reveals that majority of the adolescents were suffering from acute illnesses and another sizeable group were suffering from chronic illnesses. Among the acute conditions, upper respiratory tract infection followed by musculo-skeletal, gynecological, gastrointestinal and ENT problems while the most common chronic condition reported was anemia followed by acne and minor psychiatric illnesses like anxiety and depression.

Improvement in the quality of diagnosis and treatment for both acute and chronic illnesses among adolescents are required to be implemented in the primary health care 
level. Facilities for specialized care for the adolescent patients on specified days in a week through setting up specialty clinics and the services should be provided with experts in the respective fields. Preserving mental health at this age can be an effective tool against adoption of unhealthy life style and risky behaviors later in life. Adequate health education and awareness creation about healthy adolescent life style should be imparted at all levels.

\section{ACKNOWLEDGEMENTS}

This study was carried out with the active participation of the Interns and the Medical Officer of the Rural Health Training Centre attached to the Department. We acknowledge the effort taken by all the Interns and the Medical Officer who had participated in the data collection and also for helping to organize and carry out this study in the Training Center.

Funding: No funding sources

Conflict of interest: None declared

Ethical approval: The study was approved by the institutional ethics committee

\section{REFERENCES}

1. World Health Organization. Adolescent health epidemiology, 2014. Available at: http://www.who.int/maternal_child_adolescent/epid emiology/adolescence/en/. Accessed 1 September 2015.

2. UNICEF. India. Statistics. Adolescents, 2013. Available at: http://www.unicef.org/infobycountry/india_statistics .html. Accessed 1 September 2015.

3. Ministry of Health and Family Welfare. Strategy Handbook. Rashtriya Kishor Swasthya Karyakram, 2014. Available

http://nrhm.gov.in/images/pdf/programmes/rkskstrategy-handbook.pdf. Accessed 1 September 2015.

4. Tikoo V, Dhawan A, Pattanayak R, Chopra A. Assessment of pattern and profile of substance use among children in India. National Commission for Protection of Child Rights, 2013. Available at: http://www.ncpcr.gov.in/view_file.php?fid=17.

Accessed 1 September 2015.

5. Eissa I. The morbidity pattern among adolescents visiting primary health care centers. Saudi Med J. 2000;21(10):934-7.

6. Susmitha KM, Jyothi C, Prabakaran J. Morbidity pattern among the adolescent girls: a study in the social welfare hostels for scheduled castes, Nellore city, A.P., India. Natl J Res Community Med. 2012;1(1):01-60.

7. Sharma R, Grover V, Chaturvedi S. Health-risk behaviours related to road safety among adolescent students. Indian J Med Sci. 2007;61(12):656-62.

8. Sivagurunathan C, Umadevi R, Rama R, Gopalakrishnan S. Adolescent health: present status and its related programmes in India. Are we in the right direction? JCDR. 2015;9(3):LE01-6.

9. Hamilton SR. A relationship between perceived body image and depression: how college women see themselves may affect depression. Stud J Psychol. 2008;1:13-20.

10. Rierdan J, Koff E, Stubbs M. Depressive symptomology and body image in adolescent girls. J Early Adolesc. 1987;7(2):205-16.

11. Rierdan, J, Koff, E, Stubbs M. Gender, depression, and body image in early adolescents. J Early Adolesc. 1988;8(2):109-17.

12. Rierdan J, Koff E, Stubbs M. A longitudinal analysis of body image as a predictor of the onset and persistence of adolescent girls depression. J Early Adolesc. 1989;9(4):454-66.

13. Malhotra S, Patra B. Prevalence of child and adolescent psychiatric disorders in India: a systematic review and meta-analysis. Child Adolesc Psychiatry Ment Health. 2014;8(1):22.

14. Rani M, Karunanidhi S. Prevalence of depressive symptoms among urban adolescents in South India. J Indian Assoc Child Adolesc Ment Health. 2010;6(2):33-43.

Cite this article as: Sivagurunathan C, Gopalakrishnan S, Umadevi R, Kumar PM. Morbidity profile of adolescents reported to an urban health center in Kancheepuram district of Tamil Nadu, India. Int J Community Med Public Health 2015;2:587-91. 